\section{Post-intravitreal anti-VEGF endophthalmitis in the United Kingdom: incidence, features, risk factors, and outcomes}

\author{
Abstract \\ Purpose To describe the incidence, features, \\ management, and risk factors of post- \\ intravitreal anti-VEGF endophthalmitis \\ (PIAE) in patients undergoing treatment for \\ exudative age-related macular degeneration \\ in the United Kingdom. \\ Methods Prospective observational case \\ control study. Forty-seven cases of PIAE \\ were identified through the British \\ Ophthalmological Surveillance Unit from \\ January 2009 to March 2010. Data collected at \\ diagnosis and at 6 months follow-up \\ included patient demographics, intravitreal \\ injection details, pre- and post-injection \\ management, visual acuity, clinical features \\ and management of PIAE, causative \\ organisms, and clinical outcomes. Details \\ were compared with 200 control cases from \\ 10 control centres to identify potential risk \\ factors. \\ Results Estimated PIAE was $0.025 \%$. \\ Culture-positive PIAE incidence was $0.015 \%$. \\ Mean age of presentation was 78 years. Mean \\ number of intravitreal injections before PIAE \\ was 5 . Mean days to presentation was 5 \\ (range 1-39). Positive microbiology culture \\ was found in $59.6 \%$. The majority of \\ causative organisms were Gram positive \\ $\mathbf{( 9 2 . 8 \% ) . ~ S i g n i f i c a n t ~ r i s k ~ f a c t o r s ~ w e r e ~ f a i l u r e ~ t o ~}$ \\ administer topical antibiotics immediately after \\ the injection $(P=0.001)$, blepharitis $(P=0.006)$, \\ subconjunctival anaesthesia $(P=0.021)$, patient \\ squeezing during the injection $(P=0.021)$, \\ and failure to administer topical antibiotics \\ before anti-VEGF injection $(P=0.05)$. \\ Discussion The incidence of PIAE in the \\ United Kingdom is comparable to other \\ studies at a rate of $0.025 \%$. The most common
}

DAM Lyall', A Tey², B Foot ${ }^{3}$, STD Roxburgh², $\mathrm{M} \mathrm{Virdi}^{4}$, C Robertson ${ }^{5}$ and CJ MacEwen ${ }^{2}$

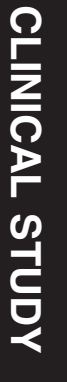

${ }^{1}$ Tennent Institute of Ophthalmology, Gartnavel General Hospital, Glasgow, UK

2Department of Ophthalmology, Ninewells Hospital and Medical School, Dundee, UK

Measures to minimise the risk of PIAE include treatment of blepharitis before injection, avoidance of subconjunctival anaesthesia, topical antibiotic administration immediately after injection with consideration to administering topical antibiotics before injection.

Eye (2012) 26, 1517-1526; doi:10.1038/eye.2012.199; published online 12 October 2012

Keywords: endophthalmitis; intravitreal injections; wet macular degeneration

\section{Introduction}

Age-related macular degeneration (ARMD) can cause severe visual loss and is the commonest cause of blind registration in patients aged over 50 years in the developed world. ${ }^{1-4}$ This can have a significant impact on quality of life for the individual and cause a significant economic burden. ${ }^{5}$ The exudative form accounts for $10 \%$ of ARMD cases with an estimated incidence of 0.45 per $1000 .^{6}$ Estimates by the Royal National Institute for the Blind and the National Institute of Clinical Excellence indicate there may be 26000 patients eligible for anti-vascular endothelial growth factor (anti-VEGF) treatments in the United Kingdom each year. ${ }^{7}$

Even with the introduction of anti-VEGF therapy, the increase in the ageing population has led to projections that cases of sight loss from exudative ARMD will increase from $\sim 145000$ to 190000 people by the year 2020 in the United Kingdom. ${ }^{8}$

Intravitreal anti-VEGF therapy is not without risks. Infectious endophthalmitis, sterile uveitis,
${ }^{3}$ British Ophthalmological Surveillance Unit, The Royal College of Ophthalmologists, London, UK

${ }^{4}$ Department of Ophthalmology, Hairmyres Hospital, East Kilbride, Scotland, UK

${ }^{5}$ Department of Mathematics and Statistics, University of Strathclyde, Glasgow, UK

Correspondence: DAM Lyall, Tennent Institute of Ophthalmology, Gartnavel General Hospital, Great Western Road, Glasgow G12 OYN, UK. Tel: + 44 (0) 141211 1039; Fax: + 44 (0) 1412112054 . E-mail: douglas_am_lyall@ hotmail.com; douglaslyall@nhs.net

Received: 31 May 2012 Accepted in revised form: 5 September 2012

Published online:

12 October 2012

Incidence and presentation data presented at Royal College of Ophthalmologists Annual Congress, Birmingham, May 2011. Risk factor data presented at Scottish Ophthalmological Club Centenary Meeting, Edinburgh, September 2011, and Royal College of Ophthalmologists Annual Congress, Liverpool, May 2012. 
retinal detachment, retinal tear, vitreous haemorrhage, raised intraocular pressure (IOP), and lenticular trauma have all been reported. ${ }^{9-13}$ Following intravitreal injection of anti-VEGF, the incidence of endophthalmitis is thought to be low with rates of between 0.02 and $0.1 \%$ previously being reported. , $^{9} 10,12,14-22$

This is the first UK-wide population-based prospective study to determine the incidence and features of endophthalmitis following intravitreal injection of antiVEGF therapy and to identify reversible risk factors for endophthalmitis so that reported incidence rates may be reduced.

\section{Materials and methods}

This was a prospective, population-based observational study of post-intravitreal anti-VEGF endophthalmitis (PIAE) with case control analysis to identify risk factors. Incident cases were identified through the British Ophthalmological Surveillance Unit (BOSU) UK-wide reporting system between January 2009 and March 2010. PIAE was defined as any case of clinically suspected infective endophthalmitis within 6 weeks of intravitreal injection of anti-VEGF therapy to treat exudative ARMD requiring antimicrobial therapy. Patients who had any simultaneous or subsequent surgical procedure following intravitreal anti-VEGF were excluded from the study.

Following case notification to BOSU, reporting ophthalmologists were sent a detailed questionnaire by the study investigators requesting data on patient demographics, presentation and features of PIAE, management, and clinical outcomes. Outcome data were obtained from follow-up questionnaires sent to the same reporting ophthalmologist 6 months after diagnosis. Ophthalmologists who did not return questionnaires received reminder letters at 2 and 3 months after the initial questionnaire was sent.

\section{Determining the denominator}

Scotland has been recognised in previous studies as a well-defined region with stable population demographics. ${ }^{23,24}$ The proportion of the Scottish population of retirement age (65 years for men and 60 years for women) has been shown to be relatively stable and representative of the whole UK population (19.0 vs $19.5 \%$, respectively). ${ }^{25}$ It was decided that the Scottish population could be used as a focus population in a similar manner to previous studies. ${ }^{23}$ The number of injections being performed in Scotland was obtained through the Scottish Macular Society (SCOTMACS), a group of medical retina consultant ophthalmologists from all areas of Scotland, who supplied data on the number of injections being performed for their individual Heath Board over the study period. This figure was subsequently compared with industry (Novartis Pharmaceutical, Surrey, UK) figures. It was determined that a total of 15581 injections of anti-VEGF, primarily Ranibizumab (Lucentis, Novartis

Pharmaceuticals), were given within the surveillance period in Scotland (compared with industry figures of $15463,<1 \%$ difference). This figure was then extrapolated to the UK population with an estimated total number of injections of 186972 given over the surveillance period.

\section{Identifying risk factors}

Control cases were randomly selected from 10 control centres throughout the United Kingdom. These centres were chosen so that control cases would be representative of the UK population of patients receiving anti-VEGF therapy for exudative ARMD and would therefore avoid any single centre or regional treatment regimen bias. In total, six centres were chosen in England, two in Scotland, one in Wales, and one in Northern Ireland. A control case was defined as a patient with exudative ARMD who received anti-VEGF therapy during the same surveillance period but who did not develop endophthalmitis. The control case proforma collected data on the same potential risk factors for PIAE that were asked in the questionnaire for incident cases of PIAE.

Statistical analysis was performed using SPSS Statistics version 18.0 (IBM, Armonk, NY, USA). The Mann-Whitney $U$-test was used to compare numerical data between categorical groups within the PIAE cohort and to compare visual acuity levels of the cohort before and after developing PIAE. With respect to case control analysis, the Pearson $\chi^{2}$ test was used to assess the relationship between categorical variables and PIAE cases. In cases where dichotomous categorical-independent variable cells had less than five cases contributing to the count, the Fisher's exact test was used instead. Confidence intervals (CIs) for the odds ratio (OR) were calculated using the exact distribution, and exact logistic regression was carried out using the elrm package in $\mathrm{R}^{26,27}$ These methods were required because some of the sample sizes in the exposure groups was small.

Local ethical board approval was granted before commencing the study.

\section{Results}

Seventy-seven incident cases were reported to BOSU. Sixty-one incident questionnaires were subsequently returned (return rate of $79.2 \%$ ). Data on 47 eligible cases 
(one bilateral) were obtained. Cases excluded included three cases occurring outwith the surveillance period and one case not meeting inclusion criteria. Ten cases were reported twice by different clinicians and were only counted once. The estimated incidence of PIAE in the United Kingdom was $0.025 \%$ ( 1 in 4000 injections).

Relevant details for risk factor analysis were compared with data from 200 eyes of 200 control cases (20 from each control centre).

\section{Patient demographics}

Most reported PIAE cases were from England (37 cases). Scotland reported four cases, and Wales and Northern Ireland reported three cases each. There were 12 males, 25 cases were in the right eye and 22 to the left (one bilateral). The mean age at presentation was $78.45 \pm 7.29$ years (range 62 to 91 years). The mean number of intravitreal injections before PIAE was $5.2 \pm 3.6$ (range 1-15). The mean number of days from injection to presentation was five (range 1-39). Forty-six PIAE cases followed intravitreal Ranibizumab (Lucentis, Novartis Pharmaceuticals) and one following intravitreal Bevacizumab (Avastin, proprietary, off label use). Of these, the majority of injections were performed in a clean room (38). Eight were performed in theatre and one in the outpatient clinic.

\section{PIAE presentation}

The most common presenting symptom of PIAE was reduction in vision (96\%). Other presenting features are shown in Figure 1a. The most common signs found were vitritis (91\%), hyperaemia $(76 \%)$, and hypopyon $(76 \%)$. Other clinical signs are shown in Figure 1b.

\section{Management}

All patients underwent intravitreal injection of antibiotics. The most common combination of intravitreal antimicrobial therapy administered was Vancomycin and Amikacin (Figure 2). Five patients (10.6\%) had an initial injection of antibiotics in combination with intravitreal steroids and three patients $(6.4 \%)$ underwent a second intravitreal injection of antibiotics.

Forty-four patients underwent vitreous biopsy with a positive yield in 26 cases (59.1\%). Nineteen patients underwent aqueous biopsy (three without a vitreous biopsy) with a positive yield in three cases (15.8\%). Two cases had an organism identified by aqueous biopsy that was not identified by vitreous biopsy. The estimated culture-positive PIAE incidence was $0.015 \%$ ( 1 in 6666 injections).
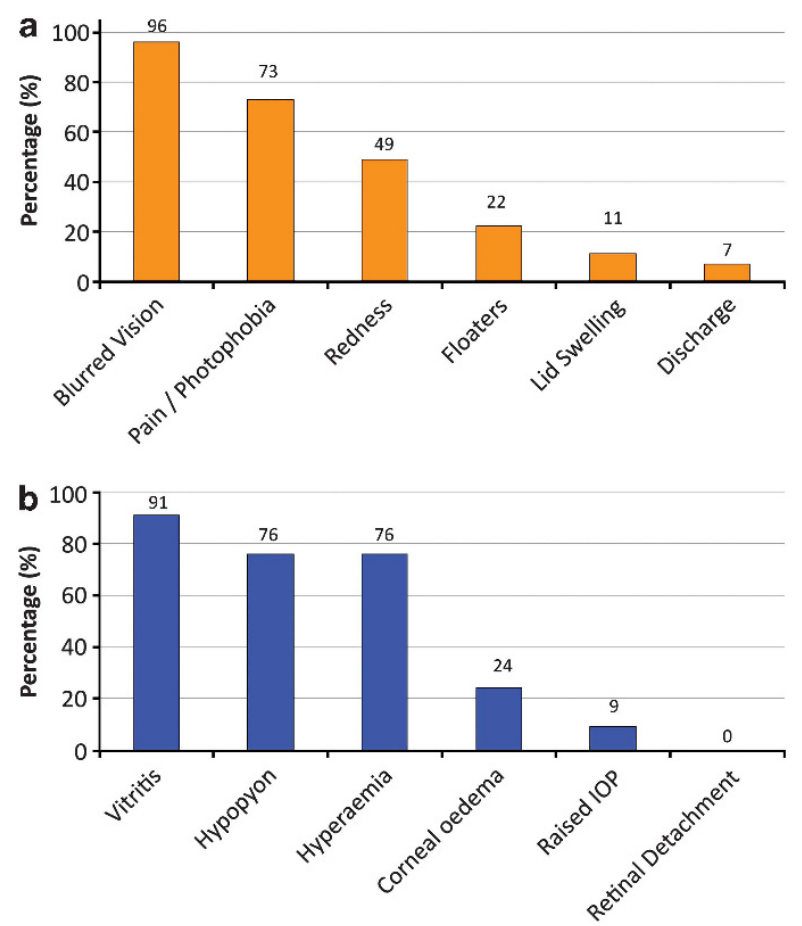

Figure 1 Presenting symptoms of PIAE (a). Presenting signs of PIAE (b).

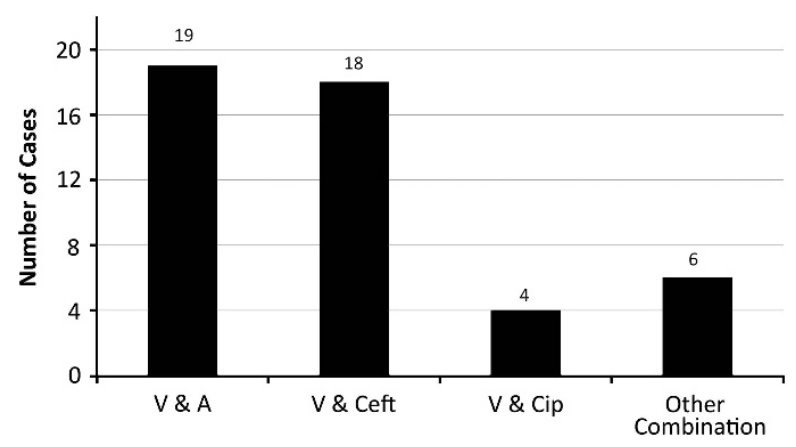

Figure 2 Initial intravitreal antimicrobial therapy given to cases of PIAE (V-vancomycin, A-amikacin, Ceft-ceftazidime, Cip-Ciprofloxacin).

\section{Vitrectomy}

A total of 16 cases underwent pars plana vitrectomy. Ten cases had this performed as part of initial management. Presenting best corrected visual acuity (BCVA) in patients undergoing early vitrectomy was $1.78 \pm 0.74$ (LogMAR) compared with $1.90 \pm 0.41$ in those who did not undergo early vitrectomy $(P=0.778)$. The 6-month follow-up BCVA of patients who underwent early vitrectomy was $1.47 \pm 0.66$ (median 1.45). This was significantly worse when compared with those who did not undergo early vitrectomy (mean $0.98 \pm 0.44$, median 1.00$)(P=0.046)$. 


\section{Microbiology}

The overall positive microbiology culture rate from all subjects was $59.6 \%$ (28 cases). The majority of organisms identified were Gram positive (92.8\%) (Table 1). The median time from anti-VEGF injection to presentation in patients with culture-positive biopsies (mean 3.9 \pm 2.0 days, median 3.0 days) was significantly less compared with the group with negative cultures (mean $8.3 \pm 9.5$ days, median 5.0 days) $(P=0.007)$.

\section{Visual outcomes}

The majority of cases (63.6\%) had worse vision after 6 months follow-up when compared with acuity pre-PIAE. Mean last recorded BCVA of the cohort before developing PIAE was $0.67 \pm 0.3$ (median 0.60). Mean BCVA on presentation with PIAE was $2.25 \pm 0.72$ (median 2.50) and BCVA after 6-month follow-up was $1.23 \pm 0.91$ (median 1.00). Six-month follow-up BCVA was significantly better than initial presentation with PIAE $(P<0.001)$ but still worse than BCVA before developing

Table 1 Causative organisms of PIAE identified by aqueous or vitreous biopsy

\begin{tabular}{lc}
\hline Organism & Number \\
\hline Staphylococcus epidermidis & 7 \\
Other coagulase negative Staphylococci & 10 \\
Staphylococcus aureus & 5 \\
Alpha haemolytic Streptococcus & 3 \\
Staphylococcus warneri & 1 \\
Haemophilus influenza & 1 \\
Aeromonas hydrophilia & 1 \\
Multiple organisms identified on PCR & 1 \\
\hline
\end{tabular}

PIAE $(P<0.001)$. Figure 3 illustrates the distribution of visual acuity of the cohort at these different time gates.

\section{Subsequent complications}

Following initial presentation, six patients subsequently developed vitreous opacities, four developed retinal detachment, one developed narrow angle glaucoma, and one developed a phthisical eye. No cases underwent evisceration or enucleation.

\section{Risk factors}

Table 2 shows the Pearson $\chi^{2}$ test and Fisher exact test results when assessing categorical variables for an association with PIAE and the Mann-Whitney $U$ level of significance for numerical data. Failure to administer a topical antibiotic immediately after the injection ( $P=0.001$, OR $30.674,95 \%$ CI 3.391-inf), the presence of blepharitis ( $P=0.006$, OR $18.193,95 \%$ CI $1.907-$ inf $)$, subconjunctival anaesthesia $(P=0.021$, OR $13.669,95 \%$ CI 1.069-728.945), the patient squeezing or moving during the injection $(P=0.021$, OR 13.669 , 95\% CI 1.069 728.945), and failure to administer a topical antibiotic before injection ( $P=0.05$, OR $1.989,95 \%$ CI $0.951-4.378$ ) were found to be significant risk factors for developing PIAE. As the incidence of these potential risk factors within our cohort is low, and very few subjects have more than one of these risk factors present, it was not possible to fit our results to a multivariate model. However, when analysing together the subset of patients who had at least one of these significant (at the 0.05 level) risk factors present, the overall OR of developing PIAE if one or more of the risk factors is present is 26.924 (95\% CI

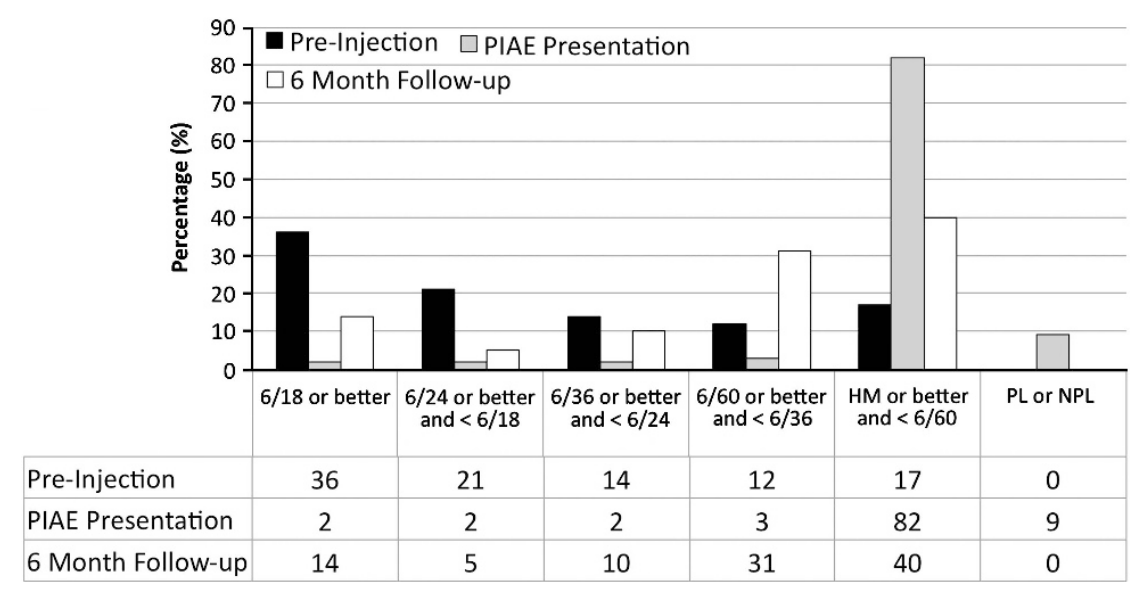

Figure 3 Visual outcomes. Grouping of CDVA of cases before developing PIAE, at presentation with PIAE, and at 6-month follow-up. Before developing PIAE, the majority of patients had a CDVA of $6 / 36$ or better. At PIAE presentation, the majority were hand movements (HM) or worse (PL-perception of light and NPL-no perception of light), with some improvement at 6 months follow-up. 
Table 2 Univariate analysis of categorical and numerical risk factors for PIAE

\begin{tabular}{|c|c|c|c|c|c|c|}
\hline \multirow[t]{2}{*}{ Independent variable } & \multirow[t]{2}{*}{$\begin{array}{l}\text { Number of PIAE } \\
\text { cases }(\%)\end{array}$} & \multirow[t]{2}{*}{$\begin{array}{c}\text { Number of control } \\
\text { cases (\%) }\end{array}$} & \multirow[t]{2}{*}{ OR } & \multicolumn{2}{|c|}{$\begin{array}{c}95 \% \\
\text { Confidence } \\
\text { interval }\end{array}$} & \multirow[t]{2}{*}{$\begin{array}{c}\text { Two-sided significance } \\
\text { value }(P)\end{array}$} \\
\hline & & & & Lower & Upper & \\
\hline \multicolumn{7}{|l|}{ Patient Characteristics } \\
\hline Male gender & $12(25.5)$ & $66(33.0)$ & 0.679 & 0.308 & 1.486 & $0.322^{\mathrm{a}}$ \\
\hline Right eye & $25(53.2)$ & $100(50)$ & 1.136 & 0.573 & 2.266 & $0.694^{\mathrm{a}}$ \\
\hline \multicolumn{7}{|l|}{ Ocular/systemic comorbidity } \\
\hline Blepharitis & $3(6.5)$ & $0(0)$ & $18.193^{\mathrm{b}}$ & 1.907 & $\operatorname{Inf}$ & $0.006^{c}$ \\
\hline Diabetes & $6(13)$ & $24(12)$ & 1.1 & 0.345 & 3.005 & $0.845^{\mathrm{a}}$ \\
\hline Immunosuppression & $1(2.2)$ & $0(0)$ & $4.346^{\mathrm{b}}$ & 0.111 & Inf & $0.187^{c}$ \\
\hline \multicolumn{7}{|l|}{ Pre-injection treatment } \\
\hline $\begin{array}{l}\text { No course of pre-injection } \\
\text { antibiotics }\end{array}$ & 43 (93.5) & $181(90.5)$ & 1.502 & 0.775 & 8.282 & $0.775^{c}$ \\
\hline \multicolumn{7}{|l|}{ Injection details } \\
\hline Use of Ranibizumab & $46(97.8)$ & $200(100)$ & $0.237^{\mathrm{b}}$ & 0 & 9.246 & $0.187^{c}$ \\
\hline Subconjunctival anaesthesia & $3(6.5)$ & $1(0.5)$ & 13.669 & 1.069 & 728.945 & $0.021^{c}$ \\
\hline 27G needle & $3(7.9)$ & $7(3.5)$ & 0.425 & 0.091 & 2.668 & $0.202^{c}$ \\
\hline Subconjunctival haemorrhage & $0(0)$ & $2(1)$ & $1.785^{\mathrm{b}}$ & 0 & 22.777 & $1^{\mathrm{a}}$ \\
\hline Raised IOP & $0(0)$ & $10(5)$ & $0.304^{\mathrm{b}}$ & 0 & 1.933 & $0.216^{\mathrm{c}}$ \\
\hline Squeezing during injection & $3(6.5)$ & $1(0.5)$ & 13.669 & 1.069 & 728.945 & $0.021^{c}$ \\
\hline $\begin{array}{l}\text { No topical antibiotic before } \\
\text { injection }\end{array}$ & $33(71.7)$ & $112(56)$ & 1.989 & 0.951 & 4.378 & $0.050^{\mathrm{a}}$ \\
\hline $\begin{array}{l}\text { No immediate post-injection } \\
\text { topical antibiotic }\end{array}$ & $4(8.7)$ & $0(0)$ & $30.674^{\mathrm{b}}$ & 3.391 & Inf & $0.001^{c}$ \\
\hline \multicolumn{7}{|l|}{ Post-injection treatment } \\
\hline $\begin{array}{l}\text { No course of post-injection } \\
\text { drops }\end{array}$ & $4(8.7)$ & $36(18)$ & 0.435 & 0.107 & 1.315 & $0.123^{\mathrm{a}}$ \\
\hline Numerical data characteristics & PIAE group & Control cases & & & & $\begin{array}{c}\text { Mann-Whitney U significance } \\
\text { value }(\mathrm{P})\end{array}$ \\
\hline Mean age (years) & $78.45 \pm 7.29$ & $79.61 \pm 8.15$ & & & & 0.258 \\
\hline $\begin{array}{l}\text { Mean pre-treatment BCVA } \\
\text { (logMAR) }\end{array}$ & $0.67 \pm 0.30$ & $0.59 \pm 0.31$ & & & & 0.639 \\
\hline $\begin{array}{l}\text { Mean last recorded BCVA } \\
\text { (logMAR) }\end{array}$ & $1.23 \pm 0.91$ & $0.58 \pm 0.41$ & & & & 0.346 \\
\hline Mean number of injections & $5.2 \pm 3.6$ & $9.3 \pm 5.2$ & & & & 0.709 \\
\hline
\end{tabular}

Abbreviations: inf, infinity; OR, odds ratio.

${ }^{\text {a }}$ Otherwise the Pearson $\chi^{2}$ was taken to be the relevant value.

${ }^{\mathrm{b}}$ Those risk factors found to be significant are highlighted in bold. In factors where the OR was found to be infinite, the exact model was used instead. ${ }^{c}$ Pearson $\chi^{2}$ and Fisher's exact test significance values and OR of categorical variables. If an independent variable had less than five cases contributing to a cell, the Fisher's exact test was taken to be the relevant $P$-value.

The $95 \%$ confidence interval upper boundary is inf when none of the controls experience an exposure of a particular risk factor and the lower boundary is zero when none of the PIAE cases were exposed to a risk factor. Numerical data analysis of patient characteristics, visual outcomes, and injection details with Mann-Whitney $U$-test values also shown

5.423-261.329). While each of these risk factors is highly predictive of developing PIAE, only one quarter of PIAE cases had one of the risk factors present. In order to identify other potential risk factors whose effect is masked by these rare but highly predictive risk factors, analysis was performed in the subset of patients who did not have any of the significant risk factors above. It was found that a course of post-injection antibiotic eye drops was protective to developing PIAE $(P=0.005$, $\mathrm{OR}=0.000,95 \%$ CI 0-0.517). 


\section{Discussion}

\section{Incidence rate}

Infective endophthalmitis is recognised as a potentially devastating complication of any intraocular procedure. It can be associated with a poor visual outcome and secondary complications, including vitreous opacities, raised IOP, optic atrophy, retinal detachment, or phthisis bulbi. $^{28}$ The incidence rate found in this study of $0.025 \%$ of PIAE is comparable to previous work that has quoted rates ranging from $0.02-0.1 \% .9,10,12,14-18,21,22$ This is the largest prospective study to ascertain an incidence rate for PIAE in the UK population when intravitreal antiVEGF is used to treat exudative ARMD.

\section{Antimicrobial therapy}

Identifying the most common causative pathogens of PIAE for a given geographical area is important so as to tailor initial empirical antimicrobial therapy and provide adequate cover. All PIAE cases received intravitreal antibiotics, which is in keeping with the widely held belief that intravitreal administration is the best method to achieve maximal concentration of antibiotics at the site of infection. ${ }^{29-31}$

\section{Microbiology}

In this study, gram-positive organisms accounted for the vast majority of cases when an organism was identified. This is in keeping with the most commonly identified pathogens causing endophthalmitis following cataract surgery and other studies analysing PIAE. ${ }^{21,28,32,33}$ The most commonly used intravitreal antibiotic combinations used in our study were vancomycin and amikacin or vancomycin and ceftazidime. Such combinations of antimicrobials, specifically vancomycin, are likely to cover the most common causative organisms in PIAE in the same way they would post-cataract endophthalmitis. ${ }^{34}$ Therefore, local protocols and empirical intravitreal antimicrobial choices for the treatment of post-cataract endophthalmitis could also be applied to PIAE management unless any local resistance patterns subsequently develop. This study did not analyse the sensitivities of culture-positive PIAE cases. However, individual units should be vigilant for the development of resistance patterns as regular prophylactic antibiotic use in patients receiving multiple injections could theoretically lead to resistance to such antibiotics in the conjunctival flora.

The overall yield rate of vitreous and aqueous sampling was $59.6 \%$. This rate is comparable to or better than other studies of endophthalmitis following intravitreal therapy and cataract surgery. $15,17,18,21,32,33,35-37$
As with endophthalmitis following cataract surgery, vitreous sampling achieved a higher organism yield rate compared with aqueous sampling. ${ }^{28,32,33}$ However, as aqueous sampling yielded an organism that was not identified by vitreous sampling in two cases, it may be optimal to perform both vitreous and aqueous sampling in the event of PIAE in order to maximise the chance of identifying a causative pathogen. The mean duration of time from injection to presentation of PIAE in cases where a causative organism was identified was significantly shorter compared with the group where no organism was identified. This suggests that more virulent organisms, causing a more aggressive clinical form of endophthalmitis, are present in more abundant numbers and are more likely to be isolated by sampling techniques.

\section{Risk factors}

Studies analysing risk factors for post-operative exogenous infectious endophthalmitis have primarily been performed following cataract surgery. ${ }^{38-40}$ While modern cataract surgery has been performed for several decades, the use of intravitreal anti-VEGF has only been used in regular practice for about 6 years. As a result, our understanding of risk factors for PIAE are comparatively limited.

Initial reports of PIAE did not allow analysis of risk factors as they were of small numbers from single institutions. ${ }^{16,17,22,41}$ More recently, larger studies have been published reporting risk factors for PIAE. Shah et $a l^{42}$ reported a case control study of 23 cases of PIAE that did not find any of the variables they studied to be significant risk factors. These included the use of a lid speculum, conjunctival displacement at the time of injection, type of anti-VEGF used, or whether the injection was given in the superior or inferior hemisphere. However, this was a study based in a single institution so it was not possible to study all the potential risk factor variables that we have. Bhatt et $a l^{14}$ did not find any significant benefit from the use of post-injection antibiotics. However, we found that administration of topical antibiotics immediately after the injection was a significantly protective factor. We also found that accounting for the highly predictive but rare risk factors identified in Table 2, a course of antibiotic eye drops following the anti-VEGF injection did offer some protection against developing PIAE.

The risk factors that we identified as being associated with an increased risk of PIAE were the presence of blepharitis and failure to administer topical antibiotics immediately after or before the injection. It can be hypothesised that treating blepharitis and antibiotic administration reduces the normal bacterial load on the 
ocular surface and therefore makes introduction of a pathogen into the vitreous cavity less likely. Using this argument, the authors hypothesise that using povidone iodine before injection would also reduce the likelihood of PIAE. However, we are unable to conclude this from this study as we relied on retrospective completion of questionnaires and it was not felt by the study group that the use of povidone iodine to clean the eye before injection would be reliably documented in medical notes. Therefore, we did not include a specific question about its use. The use of subconjunctival anaesthesia was also found to be a potential risk factor. A possible explanation for this may be that compromising the conjunctival surface before injection allows the introduction of bacteria into the subconjunctival space. This could then act as a source of infection for PIAE.

While the presence of an initial IOP spike after intravitreal injection was not found to be statistically significant, we found that no cases of PIAE had an initial IOP spike following intravitreal injection but that 10 control cases $(5 \%)$ did. It has previously been proposed that gaping wounds or a low IOP at the end of ocular surgery results in passive diffusion of fluid, which contains normal bacterial flora, from the ocular surface, through the wound and into the eye. ${ }^{43,44}$ It may be possible that raised IOP following an intravitreal injection prevents this passive diffusion of fluid. Therefore, there would be a reduced likelihood of normal bacterial flora gaining access to the vitreous cavity with the potential to cause endophthalmitis.

\section{Case definition}

Cases that were culture positive and culture negative were included in the analysis. Even in the context of negative microbiological cultures, an infectious aetiology cannot be excluded and all cases of presumed PIAE should be treated as infectious in the first instance so to avoid unnecessary delay. ${ }^{31}$ We believe that this study provides useful information on the presentation, management, and outcomes of clinically diagnosed PIAE regardless of whether a culture-positive aetiology can be made, as both require urgent treatment on presentation.

A time limit of 6 weeks was set on our case definition even though we appreciate that late-onset endophthalmitis could occur after this period. The clinical presentation and management of late-onset endophthalmitis can be different from the acute-onset form and can be caused by a different spectrum of organisms. ${ }^{45-47}$ This study aimed to focus on the features and outcomes of acute-onset endophthalmitis. We set this 6-week time limit in order to make our findings comparable to other published results. ${ }^{28,47}$

\section{Possible sources of error}

This study relied on incident cases of PIAE being reported to the investigators via BOSU. Any surveillance framework may underestimate incidence rates if the system fails to identify all incident cases. ${ }^{48}$ However, BOSU is an established facility in the United Kingdom that has been running for more than 10 years, contacts all senior ophthalmic clinicians in the United Kingdom on a monthly basis, and has a high profile in the UK ophthalmic community: all of which minimise under reporting. We independently contacted all medical retina specialists in Scotland via SCOTMACS to ascertain whether they were aware of any incident cases of PIAE outwith the four reported to BOSU ( $8.5 \%$ of the whole cohort). We did not identify any unreported cases. While one cannot necessarily infer from this that the reporting rate was $100 \%$ for the whole of the United Kingdom, it demonstrates that there was no systematic underreporting from the area we sampled and it is unlikely that the true incident rate differs significantly from our estimate, although this is likely to be a minimal estimate. It is also likely that other methods of data collection result in failure to capture all relevant data to either a similar or greater degree, thus making our estimation just as reliable. ${ }^{49}$ The nation-wide coverage of the BOSU facility also allows data on a higher number of cases to be collected from a larger geographical area, ensuring that collected data are free of regional or single centre bias and is representative of the wider population.

Owing to the relative rarity of PIAE, a case control study methodology was chosen to study risk factors. In order to minimise any bias, control cases were taken from a variety of centres across a large geographical area so as to be representative of the UK population of patients receiving intravitreal anti-VEGF for exudative ARMD. A case control study allowed data on a relatively large group to be collected over a short period of time. This is of particular importance in this context as the use of intravitreal anti-VEGF is increasing exponentially and indentifying potential risk factors for PIAE in a short time frame is clinically important.

\section{Conclusions}

We have estimated the incidence of PIAE following intravitreal treatment for neovascular ARMD in the United Kingdom to be $0.025 \%$ with a culture-positive rate of $0.015 \%$. We have found that the most common causative organisms were Gram positive. Steps to minimise the risk of PIAE include adequate treatment of blepharitis and eyelid check before the injection, avoidance of sub-conjunctival anaesthesia, and administration of topical antibiotics immediately after 
injection with consideration to administering topical antibiotics before the injection. The results of this study provide ophthalmologists with useful data when consenting patients for intravitreal anti-VEGF therapy. It also provides information on the presentation of PIAE and the microbiological profile that can be used to assist in the management of such cases.

\section{Summary}

What was known before

- Infectious endophthalmitis is a recognised complication of intravitreal anti-VEGF therapy when used to treat exudative age-related macular degeneration.

\section{What this study adds}

- The estimated incidence rate of presumed infective endophthalmitis following intravitreal anti-VEGF therapy in the United Kingdom is $0.025 \%$.

- Positive microbiology results can be achieved in $59.6 \%$ of cases through either vitreous or anterior chamber sampling.

- Gram-positive bacteria are the main causative organism of infective post-intravitreal anti-VEGF endophthalmitis in the United Kingdom.

- Significant risk factors for developing infectious endophthalmitis following intravitreal injection of antiVEGF therapy include failure to administer topical antibiotics immediately after the injection, the presence of blepharitis, the use of subconjunctival anaesthesia, patient squeezing during the injection, and no use of topical antibiotics before performing anti-VEGF injection.

\section{Conflict of interest}

The authors declare no conflict of interest.

\section{Acknowledgements}

We would like to thank the BOSU for the opportunity to perform this study. We are grateful to Fight for Sight for their funding support. Fight for Sight Research Bursary was awarded to perform this study through the BOSU. We thank Dr Kimia Ziahosseini for advice on analysis of incident data and the following consultants who reported incident cases of PIAE to BOSU and assisted with data collection: Dr A Armbrecht, Mr S Armstrong, Mr N Beare, Mr A Browning, Mr RL Burton, Professor U Chakravarthy, Mr HC Chen, Mrs JK Chinna, Miss H Cook, Mr M Costen, Mr J Deane, Mrs S Dhar-munshi, Miss SM Downes, Mr R Gupta, Dr HM Hammer, Mrs BA Harney, Mr E Hughes, Mr N Islam, Mr J Keenan, Mr A King, Mr GR Kirby, Mr JNP Kirkpatrick, Mr S Mahmood, Mr J Mathews, Mr T McMullan, Mr R McPherson, Mr KB Mills, Mr DA Mulholland, Dr A Purdie, Mr RJ Pushpanathan, Mr P Rao, Mr M Saeed, Mr RAH Scott,
Ms G Silvestri, Mr K Sim, Mr A Sinha, Miss S Sivaprasad, Mr YC Yang, and Mr N Zaman. We would also like to thank the following clinicians who assisted in data collection of control cases at their centres: Mr N Beare (Royal Liverpool University Hospital), Mr C Blyth and Dr M Popiela (University Hospital of Wales), Dr P Cackett (Princess Alexandra Eye Pavillion), Dr M Gavin (Gartnavel General Hospital), Mr N Lee (Hillingdon Hospital), Mr M Majid (Bristol Eye Hospital), Mr M McKibbin (St James's University Hospital), Miss J Silvestri and Dr S Twaij (Royal Victoria Hospital), Mr J Talks (Royal Victoria Infirmary), and Mr A Tufail (Moorfields Eye Hospital).

\section{References}

1 Augood CA, Vingerling JR, de Jong PT, Chakravarthy U, Seland J, Soubrane G et al. Prevalence of age-related maculopathy in older Europeans: the European Eye Study (EUREYE). Arch Ophthalmol 2006; 124: 529-535.

2 Bunce C, Wormald R. Leading causes of certification for blindness and partial sight in England \& Wales. BMC Public Health 2006; 6: 58.

3 Klein R, Klein BE, Linton KL. Prevalence of age-related maculopathy. The Beaver Dam Eye Study. Ophthalmology 1992; 99: 933-943.

4 Mitchell P, Smith W, Attebo K, Wang JJ. Prevalence of agerelated maculopathy in Australia. The Blue Mountains Eye Study. Ophthalmology 1995; 102: 1450-1460.

5 Brown MM, Brown GC, Stein JD, Roth Z, Campanella J, Beauchamp GR. Age-related macular degeneration: economic burden and value-based medicine analysis. Can J Ophthalmol 2005; 40: 277-287.

6 Owen CG, Fletcher AE, Donoghue M, Rudnicka AR. How big is the burden of visual loss caused by age related macular degeneration in the United Kingdom? $\mathrm{Br} \mathrm{J}$ Ophthalmol 2003; 87: 312-317.

7 NICE. HTA Ranibizumab and Pegaptanib for the treatment of AMD. Final Scope 2006.

8 Minassian DC, Reidy A, Lightstone A, Desai P. Modelling the prevalence of age-related macular degeneration (20102020) in the UK: expected impact of anti-vascular endothelial growth factor (VEGF) therapy. $\mathrm{Br} J$ Ophthalmol 2011; 95: 1433-1436.

9 Brown DM, Kaiser PK, Michels M, Soubrane G, Heier JS, Kim RY et al. Ranibizumab vs verteporfin for neovascular age-related macular degeneration. N Engl J Med 2006; 355: 1432-1444.

10 Day S, Acquah K, Mruthyunjaya P, Grossman DS, Lee PP, Sloan FA. Ocular complications after anti-vascular endothelial growth factor therapy in medicare patients with age-related macular degeneration. Am J Ophthalmol 2011; 152: $266-272$.

11 Good TJ, Kimura AE, Mandava N, Kahook MY. Sustained elevation of intraocular pressure after intravitreal injections of anti-VEGF agents. Br J Ophthalmol 2011; 95: 1111-1114.

12 Rosenfeld PJ, Brown DM, Heier JS, Boyer DS, Kaiser PK, Chung CY et al. Ranibizumab for neovascular age-related macular degeneration. $N$ Engl J Med 2006; 355: 1419-1431. 
13 Saeed MU, Prasad S. Management of cataract caused by inadvertent capsule penetration during intravitreal injection of ranibizumab. J Cataract Refract Surg 2009; 35: 1857-1859.

14 Bhatt SS, Stepien KE, Joshi K. Prophylactic antibiotic use after intravitreal injection: effect on endophthalmitis rate. Retina 2011; 31: 2032-2036.

15 Cheung CS, Wong AW, Lui A, Kertes PJ, Devenyi RG, Lam WC. Incidence of endophthalmitis and use of antibiotic prophylaxis after intravitreal injections. Ophthalmology 2012; 119: 1609-1614.

16 Diago T, McCannel CA, Bakri SJ, Pulido JS, Edwards AO, Pach JM. Infectious endophthalmitis after intravitreal injection of antiangiogenic agents. Retina 2009; 29: 601-605.

17 Fintak DR, Shah GK, Blinder KJ, Regillo CD, Pollack J, Heier JS et al. Incidence of endophthalmitis related to intravitreal injection of bevacizumab and ranibizumab. Retina 2008; 28: 1395-1399.

18 Inoue M, Kobayakawa S, Sotozono C, Komori H, Tanaka K, Suda Y et al. Evaluation of the incidence of endophthalmitis after intravitreal injection of anti-vascular endothelial growth factor. Ophthalmologica 2011; 226: 145-150.

19 Jonas JB, Spandau UH, Rensch F, Von Baltz S, Schlichtenbrede F. Infectious and noninfectious endophthalmitis after intravitreal bevacizumab. J Ocul Pharmacol Ther 2007; 23: 240-242.

20 McCannel CA. Meta-analysis of endophthalmitis after intravitreal injection of anti-vascular endothelial growth factor agents: causative organisms and possible prevention strategies. Retina 2011; 31: 654-661.

21 Moshfeghi AA, Rosenfeld PJ, Flynn HW Jr, Schwartz SG, Davis JL, Murray TG et al. Endophthalmitis after intravitreal anti-vascular endothelial growth factor antagonists: a sixyear experience at a university referral center. Retina 2011; 31: 662-668.

22 Pilli S, Kotsolis A, Spaide RF, Slakter J, Freund KB, Sorenson J et al. Endophthalmitis associated with intravitreal antivascular endothelial growth factor therapy injections in an office setting. Am J Ophthalmol 2008; 145: 879-882.

23 Desai P, MacEwen CJ, Baines P, Minassian DC. Incidence of cases of ocular trauma admitted to hospital and incidence of blinding outcome. Br J Ophthalmol 1996; 80: 592-596.

24 Mitry D, Charteris DG, Yorston D, Siddiqui MA, Campbell $\mathrm{H}$, Murphy AL et al. The epidemiology and socioeconomic associations of retinal detachment in Scotland: a two-year prospective population-based study. Invest Ophthalmol Vis Sci 2010; 51: 4963-4968.

25 Key population and vital statistics No.34, 2007 ed. Released 24 April 2009. Office for National Statistics (www.ons. gov.uk).

26 R Development Core Team. $R$ : A language and environment for statistical computing. R Foundation for statistical computing: Vienna, Austria, 2011.

27 Zamar D, McNeney B, Graham J. elrm: software implementing exact-like inference for logistic regression models. J Stat Softw 2007; 21.

28 Kamalarajah S, Silvestri G, Sharma N, Khan A, Foot B, Ling $\mathrm{R}$ et al. Surveillance of endophthalmitis following cataract surgery in the UK. Eye (Lond) 2004; 18: 580-587.

29 Lopez-Cabezas C, Muner DS, Massa MR, Mensa Pueyo JM. Antibiotics in endophthalmitis: microbiological and pharmacokinetic considerations. Curr Clin Pharmacol 2010; 5: $47-54$

$30 \mathrm{Ng}$ JQ, Morlet N, Pearman JW, Constable IJ, McAllister IL, Kennedy CJ et al. Management and outcomes of postoperative endophthalmitis since the endophthalmitis vitrectomy study: the Endophthalmitis Population Study of Western Australia (EPSWA)'s fifth report. Ophthalmology 2005; 112: 1199-1206.

31 Packer M, Chang DF, Dewey SH, Little BC, Mamalis N, Oetting TA et al. Prevention, diagnosis, and management of acute postoperative bacterial endophthalmitis. J Cataract Refract Surg 2011; 37: 1699-1714.

32 Almeida DR, Miller D, Alfonso EC. Anterior chamber and vitreous concordance in endophthalmitis: implications for prophylaxis. Arch Ophthalmol 2010; 128: 1136-1139.

33 Mollan SP, Gao A, Lockwood A, Durrani OM, Butler L. Postcataract endophthalmitis: incidence and microbial isolates in a United Kingdom region from 1996 through 2004. J Cataract Refract Surg 2007; 33: 265-268.

34 van Duijn PJ, Dautzenberg MJ, Oostdijk EA. Recent trends in antibiotic resistance in European ICUs. Curr Opin Crit Care 2011; 17: 658-665.

35 Barza M, Pavan PR, Doft BH, Wisniewski SR, Wilson LA, Han DP et al. Evaluation of microbiological diagnostic techniques in postoperative endophthalmitis in the Endophthalmitis Vitrectomy Study. Arch Ophthalmol 1997; 115: $1142-1150$.

36 Irigoyen C, Ziahosseini K, Morphis G, Stappler T, Heimann $\mathrm{H}$. Endophthalmitis following intravitreal injections. Graefes Arch Clin Exp Ophthalmol 2012; 250: 499-505.

37 Sheng Y, Sun W, Gu Y, Lou J, Liu W. Endophthalmitis after cataract surgery in China, 1995-2009. J Cataract Refract Surg 2011; 37: 1715-1722.

38 Kamalarajah S, Ling R, Silvestri G, Sharma NK, Cole MD, Cran G et al. Presumed infectious endophthalmitis following cataract surgery in the UK: a case-control study of risk factors. Eye (Lond) 2007; 21: 580-586.

39 Lundstrom M, Wejde G, Stenevi U, Thorburn W, Montan P. Endophthalmitis after cataract surgery: a nationwide prospective study evaluating incidence in relation to incision type and location. Ophthalmology 2007; 114: 866-870.

40 Montan PG, Koranyi G, Setterquist HE, Stridh A, Philipson BT, Wiklund K. Endophthalmitis after cataract surgery: risk factors relating to technique and events of the operation and patient history: a retrospective case-control study. Ophthalmology 1998; 105: 2171-2177.

41 Mason JO 3rd, White MF, Feist RM, Thomley ML, Albert MA, Persaud TO et al. Incidence of acute onset endophthalmitis following intravitreal bevacizumab (Avastin) injection. Retina 2008; 28: 564-567.

42 Shah CP, Garg SJ, Vander JF, Brown GC, Kaiser RS, Haller JA. Outcomes and risk factors associated with endophthalmitis after intravitreal injection of anti-vascular endothelial growth factor agents. Ophthalmology 2011; 118: 2028-2034.

43 Aralikatti AK, Needham AD, Lee MW, Prasad S. Entry of antibiotic ointment into the anterior chamber after uneventful phacoemulsification. J Cataract Refract Surg 2003; 29: 595-597.

44 Werner L, Sher JH, Taylor JR, Mamalis N, Nash WA, Csordas JE et al. Toxic anterior segment syndrome and possible association with ointment in the anterior chamber following cataract surgery. J Cataract Refract Surg 2006; 32: 227-235.

45 Aldave AJ, Stein JD, Deramo VA, Shah GK, Fischer DH, Maguire JI. Treatment strategies for postoperative Propionibacterium acnes endophthalmitis. Ophthalmology 1999; 106: 2395-2401. 
46 Clark WL, Kaiser PK, Flynn HW Jr, Belfort A, Miller D, Meisler DM. Treatment strategies and visual acuity outcomes in chronic postoperative Propionibacterium acnes endophthalmitis. Ophthalmology 1999; 106: 1665-1670.

47 The Endophthalmitis Study Group. Results of the Endophthalmitis Vitrectomy Study. A randomized trial of immediate vitrectomy and of intravenous antibiotics for the treatment of postoperative bacterial endophthalmitis.
Endophthalmitis Vitrectomy Study Group. Arch Ophthalmol 1995; 113: 1479-1496.

48 Foot B, Stanford M, Rahi J, Thompson J. The British Ophthalmological Surveillance Unit: an evaluation of the first 3 years. Eye (Lond) 2003; 17: 9-15.

49 Kelly SP, Barua A. A review of safety incidents in England and Wales for vascular endothelial growth factor inhibitor medications. Eye (Lond) 2011; 25: 710-716. 